\title{
手指消毒薬倍量キャンペーン実施内容とその効果
}

\author{
浜田 幸宏 1,2$) \cdot$ 岡前 朋子1） - 加藤由紀子1） - 久留宮 愛1) \\ 高橋 知子 1 - 末松 寛之 ${ }^{1)} \cdot$ 川澄 紀代 1,2$) \cdot$ 平井 潤 1,3 \\ 山岸 由佳(1,3) · 松浦 克彦2) · 三鴨 廣繁1,3)
}

\section{Effectiveness and Approach of Campaign to Use Alcohol-Based Hand Rub}

Yukihiro Hamada ${ }^{1,2)}$, Tomoko OKamaE ${ }^{1)}$, Yukiko Kato $^{1}$, Ai KurumiYa ${ }^{1}$, Tomoko TAKahashi ${ }^{1)}$, Hiroyuki Suematsu ${ }^{1}$, Noriyo KaWASUmi ${ }^{1,2)}$, Jun HiraI ${ }^{1,3)}$, Yuka YAMAGISHI ${ }^{1,3)}$, Katsuhiko MatsuURA ${ }^{2)}$ and Hiroshige MiKAMO ${ }^{1,3)}$

${ }^{1)}$ Department of Infection Control and Prevention, ${ }^{2)}$ Department of Pharmacy,

3) Department of Clinical Infectious Diseases, Aichi Medical University Hospital

( 2015 年 8 月 11 日 受付 $\cdot 2015$ 年 11 月 6 日 受理)

要旨

手指衛生は感染防止技術の根幹をなす。今回，我々は当院に抢いて 2013 年 2 月から 2014 年 3 月までに手指消毒薬キャンペーンを実施し消毒薬の使用量と healthcare-associated methicillinresistant Staphylococcus aureus (HA-MRSA) 検出率への影響を調査した. キャンペーン前の消毒量 は 5.8 (L/1000 patient-days)であったのに対し，キャンペーン後は 11.6 (L/1000 patient-days) と 有意に増大し $(\mathrm{p}<0.01)$, MRSA 検出率 $(\%)$ は 2.5 から 1.5 に有意に低下した $(\mathrm{p}<0.01)$ ．キャン ペーンによる消毒薬の使用量の増大の結果, HA-MRSA 検出率の低下に繋がった.

Key words : 手指衛生，キャンペーン，消毒薬，手指消毒薬

2002 年に米国疾病管理センター (Centers for Disease Control and Prevention: CDC)が公表した「医療現場に 打ける手指衛生のためのガイドライン」1)では，手指が 目に見えて污れていない場合, 速乾性手指消毒薬が手指 衛生の基本とされている。 また，2009 年に WHO (World Health Organization: WHO)が公表した手指衛 生ガイドラインの中では, 消毒薬の使用量の目安として 1000 患者あたり $20 \mathrm{~L}(20 \mathrm{~L} / 1000$ patient-days $)$ として いる2)。

近年では, 具体的な医療関連感染対策の一つとして, antimicrobial stewardship ${ }^{3)}$ の観点から抗菌薬や消毒薬 の使用量の評価が実施されるようになってきた。しか し, 医療関連感染対策に扔いて最も基本的かつ重要な対 策は手指衛生である。手指衛生の強化は, 医師, 看護 師, 薬剂師, 放射線技師, 臨床検查技師, 医療事務員な ぞ全職員抢よび関係者で取り組むべき課題であるが，病

愛知医科大学病院 ${ }^{1}$ 感染制御部, 2 薬剤部, 3) 感染症科
院全体として消毒薬の使用量の増大には各個人の継続的 なモチべーションの向上が欠かせない，このような状況 でリーダーシップを取るのが，感染対策チーム(infection control team, 以下 ICT) である4)。このような背景 の中, 愛知医科大学病院 (以下当院) ICT では, 手指消 毒用アルコール製剤請求量 15 (L/1000 patient-days)を 目標とした「アルコール製剤倍量キャンペーン」を実施 し, その内容と効果について後方視的に検討した.

2013 年 2 月から 2014 年 3 月に当院全職員 (リンク ナース含む)を対象としキャンペーンを実施した。具体 的な活動として, 通常より多くのポスター貼付 (148 部 署+50 枚), 各部署への手指衛生強化依頼文配布, ICN による直接観察 (医師 48 名, 看護師 273 名), 結果のフ ィードバックは外来と入院に分け，WHO の私の手指衛 生 5 つの瞬間を経時的に実施した。 またキャンペーン 期間中に改良版手指消毒回数計測装置 (カウンター) を導 入し，12 部署 150 名の看護師について試験的に手指遵 守率の向上に努めた(図 1)。キャンペーンの効果につい 


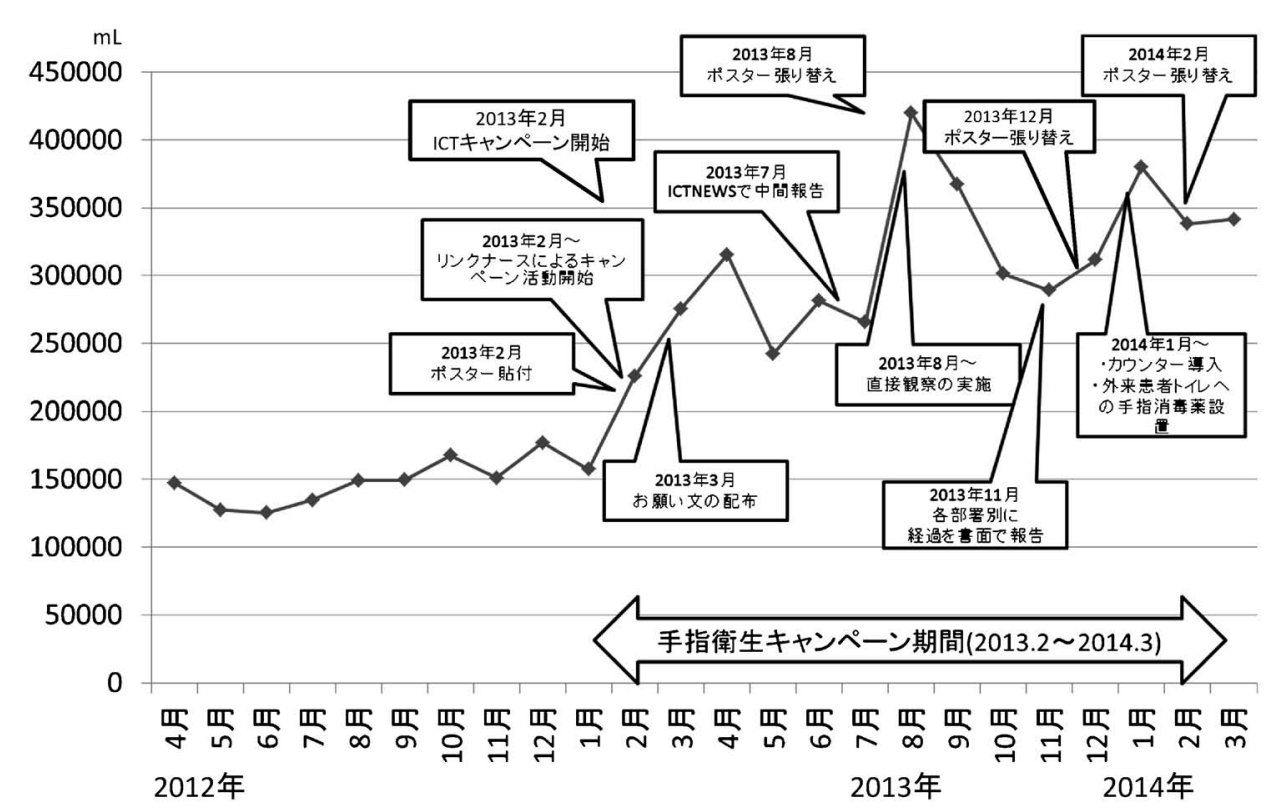

図 1 キャンペーン活動の経過と手指消毒用アルコール製剤の請求量の推移

折れ線は 1 ヶ月毎の手指消毒用アルコール製剂の請求量を示し, 吹き出しにはキャンペーン中の詳細な活動内容を記載.

ては, 消毒薬請求量 $\{$ 消毒薬請求量/のべ入院患者数 $(\mathrm{L} /$ 1000 patient-days) \} と methicillin-resistant Staphylococcus aureus (MRSA) 検出率 $(\%)$ を(MRSA 検出数/延べ 入院患者数 $\times 1000)$ をキャンペーン前後では $\chi^{2}$ 検定 で，消毒量は対応のない $t$ 検定を用いて評価した。 MRSA 検出率は, キャンペーン前 10 ヶ月 (2012 年 4 月 から 2013 年 3 月) とキャンペーンの 14 ヶ月間の合計検 出数で統計解析を行い, そのデータから従属变数を 1 ヶ月毎とし，そのデータから消毒薬請求量および MRSA 検出率に関する線形回帰分析を行った.

MRSA 検出率の算出には院内微生物検査室において 自動同定 ·薬剂感受性機器の全自動迅速同定感受性測定 装置 $\left(R_{\text {RISUS }}^{\circledR}\right.$, 日水製薬秼)を用いて同定，感受性を 実施した。oxacillin の最小発育阻止濃度 (MIC) が $4 \mu \mathrm{g} /$ $\mathrm{mL}$ 以上を示した株を MRSA とし， 3 ヶ月間に同一検 体から検出された株は除外した。なお，MRSA 検出率 は同一患者からの別検体の分離は別件としてカウントし た。

キャンペーン前後における病院全体の月平均の消毒薬 の請求量 (L/1000 patient-days)は, キャンペーン前で 5.8 であったのに対し, キャンペーン後は 11.6 と有意 $(\mathrm{p}<0.01)$ に増加した. MRSA 検出率の月平均では, キ ヤンペーン前で 2.5 であったのに対し, キャンペーン後 では 1.5 と有意 $(\mathrm{p}<0.01)$ に低下した（図 2$)$. また，時 系列線形回帰分析の結果, 消毒薬請求量の増加 $\left(\mathrm{R}^{2}=\right.$ $0.803, \mathrm{p}<0.01)$ に伴い，MRSA 検出率が有意に低下す ることが明らかとなった $\left(\mathrm{R}^{2}=0.652, \mathrm{p}<0.01\right)$. 次に, 病棟へ即時報告するために MRSA 検出数/総検体数 $\times$
100 で算出した MRSA 検出数が上位であった $(\mathrm{A} \sim \mathrm{E}$ 病 棟) 5 病棟に関しても同様に解析した結果, $\mathrm{A}$ 病棟(脳 神経外科)では消毒薬請求量が 9.2 から 15.3 (L/1000 patient-days) に増加し, MRSA 検出率は 6.0 から 2.8 に低下, B 病棟 (消化器外科)では消毒量が 4.6 から 11.0 (L/1000 patient-days) に増加し, MRSA 検出率は 12.6 から 4.2 に低下，C 病棟 (神経内科)では消毒量が 10.2 から 14.7 (L/1000 patient-days)に増加し, MRSA 検出 率は 5.7 から 1.8 に低下, D 病棟 (ICU) では消毒量が 11.1 から 33.6 (L/1000 patient-days)に増加し, MRSA 検出率は 4.5 から 1.8 に低下し, 上記結果は消毒薬請求 量の有意 $(\mathrm{p}<0.01)$ な増加と MRSA 検出率の有意 $(\mathrm{p}<$ 0.01)な低下に繋がった.しかしながら, E 病棟 (泌尿器 科)では消毒薬請求量が 5.7 から 9.1 (L/1000 patientdays) に有意に増加し, MRSA 検出率は 5.6 から 5.0 に 低下したものの有意差は認められなかった $(\mathrm{p}=0.59)$. 以上より，キャンペーンを実施したことで目標の 15 (L/1000 patient-days)には達成しなかったものの, 病 院全体および各病棟単位で一定の効果が得られたと考え られる。

今回, 私立大学感染対策協議会のサイトビジットの際 に, 消毒薬の使用量の低さを指摘されたことが契機とな り，アルコール使用量増加キャンペーンを企画した．ア ルコール使用量の目標值として 15 (L/1000 patientdays)に設定したが，WHO が推奨している 20 (L/1000 patient-days)を目標にするとハードルを上げて職員が諦 めてしまうという懸念があった. Pittet ら5) は, キャン ペーンを実施し 4 年間かけて 4.1 から $15.4(\mathrm{~L} / 1000$ 


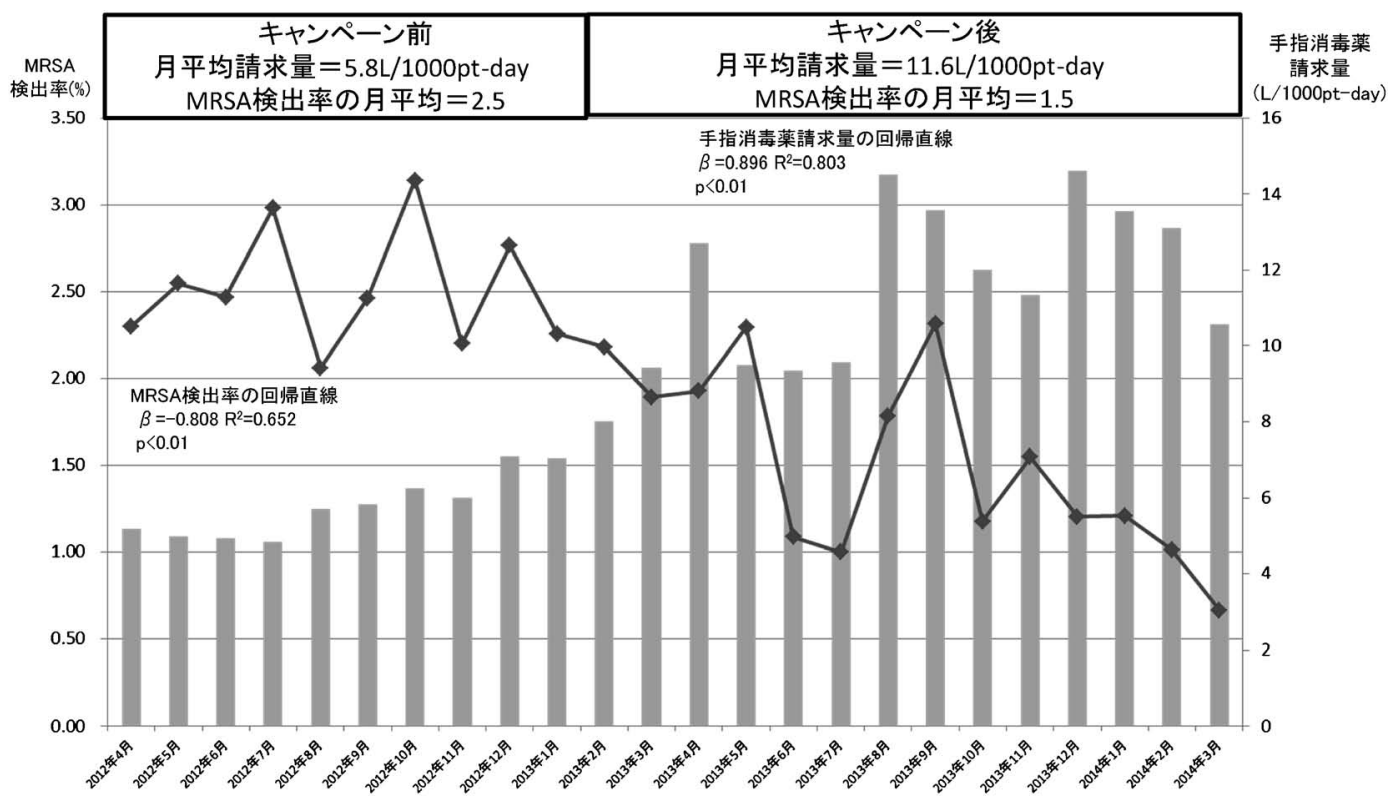

図 2 病院全体の手指消毒用アルコール製剤請求量 (L/1000 pt-days) と MRSA 検出率 (MRSA 検出数/延べ入院患者数 $\times 1000)$ の毎月の推移

折れ線には MRSA 検出率，棒グラフには手指消毒用アルコール製剂の請求量を 1 ヶ月間毎で示し，線形回帰分析として $\mathrm{R}^{2}$ は 決定係数, $\beta$ は回帰係数, $\mathrm{p}$ 值が 0.01 未満を統計学的有意水準とした.

patient-days)に達成し, 感染率や感染コストの低下を報 告していたことが挙げられる。一方で, 同文献では, 継 続的に 3 年後に 30.6 (L/1000 patient-days) まで消毒薬 請求量が増加したが，感染率に大きな変化はなかったと も報告している. 手指衛生に関しては, 継続した啓発活 動が，その遵守率を向上させると報告6,7されれており， 日本に打いてもそのような取り組反の結果, 有意差はな かったものの経年的には MRSAの新規検出数は減少傾 向を示したことが報告8)されている. 今後, 当院でも継 続的にキャンペーンを実施しながら全職員がモチベーシ ヨンを保てるような工夫を取り入れ，今年度は，アル コール使用量の目標值を 20 (L/1000 patient-days) に掲 げている. 今回 MRSA 検出率に有意差を認めなかった 病棟も再評価することで消毒量の目標値の予測モデルが 構築できる可能性がある。

我々は, 以前, 新規 MRSA 検出率に対する寄与率々 して消毒薬が $20.7 \%$ であったことを報告した ${ }^{9)}$. しか し, 既報9)の結果では経時的な変化を捉えることは困難 であった，今回の時系列回帰分析により, 経時的な消毒 薬量請求量の増加が MRSA 検出率の低下に繋がること が明白となった. 今回の追加解析を加えたことで我々が 検証した主成分分析を用いた MRSA 検出率の要因探索 モデルのさらなる有用性が立証できたと考える。

本研究の一部は, 第 30 回日本環境感染学会総会で発表した ものである.
利益相反自己申告 : 申告すべきものなし.

文献

1) Boyce JM, Pittet D: Guideline for hand hygiene in health-care settings. Recommendations of the healthcare infection control practices advisory committee and the HICPAC/SHEA/APIC/IDSA Hand Hygiene Task Force. MMWR Recomm Rep 2002; 25(51): 1-45.

2) WHO Guidelines on Hand Hygiene in Health Care; http://whqlibdoc.who.int/publications/2009/978924159 7906_eng.pdf. accessed June 1, 2015.

3) Dellit TH, Owens RC, McGowan JE Jr, Gerding DN, Weinstein RA, Burke JP, et al.: Infectious Diseases Society of America and the Society for Healthcare Epidemiology of America guidelines for developing an institutional program to enhance antimicrobial stewardship. Clin Infect Dis 2007; 44(2): 159-77.

4）浜田幸宏, 山岸由佳, 加藤由紀子, 岡前朋子, 久留宮 愛, 末松寛之, 他 :【小児感染症の予防 2014】社会的組 織(システム)に抢減染の予防 医療関連感染対策の 組織化. 小肾臨 2014; 67(4): 665-70.

5) Pittet D, Sax H, Hugonnet S, Harbarth S: Cost implications of successful hand hygiene promotion. Infect Control Hosp Epidemiol 2004; 25(3): 264-6.

6) Harbarth S, Pittet D, Grady L, Zawacki A, Potter-Bynoe $\mathrm{G}$, Samore MH, Goldmann DA: Interventional study to evaluate the impact of an alcohol-based hand gel in improving hand hygiene compliance. Pediatr Infect Dis J 2002; 21(6): 489-95.

7) Avila-Aguero ML, Umana MA, Jimenez AL, Faingezicht I, Paris MM: Handwashing practices in a tertiary-care, pediatric hospital and the effect on an educational program. Clin Perform Qual Health Care 1998; 6(2): $70-2$. 
8）西岡達也，岡本和恵，井澤初美，但馬重俊，服部英喜 : 速乾性手指消毒剂による手指衛生の遵守率向上への取り 組みとその評価. 環境感染誌 2010(1); 25: 37-40.

9）浜田幸宏, 山岸由佳, 加藤由紀子, 末松寛之, 岡前朋 子, 久留宮愛, 他 : 主成分分析を用いた MRSA 検出率
の要因探索. 環境感染誌 2015; 30(4): 262-7.

〔連絡先：干480-1195 愛知県長久手市岩作雁又 1 番地 1 愛知医科大学病院感染制御部 浜田幸宏

E-mail: hamayuki@aichi-med-u.ac.jp]

\title{
Effectiveness and Approach of Campaign to Use Alcohol-Based Hand Rub
}

\author{
Yukihiro Hamada ${ }^{1,2)}$, Tomoko OkAmaE ${ }^{1)}$, Yukiko KATO ${ }^{1)}$, Ai KurumiYa ${ }^{1)}$, \\ Tomoko TAKAHAShi ${ }^{1)}$, Hiroyuki Suematsu') ${ }^{1)}$, Noriyo KaWASUmi ${ }^{1,2)}$, Jun Hirai ${ }^{1,3)}$, \\ Yuka Yamagishi ${ }^{1,3)}$, Katsuhiko MatsuUra ${ }^{2)}$ and Hiroshige Mikamo ${ }^{1,3)}$ \\ 1) Department of Infection Control and Prevention, ${ }^{2)}$ Department of Pharmacy, \\ 3) Department of Clinical Infectious Diseases, Aichi Medical University Hospital
}

\begin{abstract}
Hand hygiene plays a major role in preventing infections. We analyzed the effect of a hand hygiene campaign for decreasing healthcare-associated methicillin-resistant Staphylococcus aureus (HA-MRSA) at our hospital. Monthly data were retrospectively reviewed from February 2013 to March 2014. Consumption values of alcohol-based hand scrub before and after the campaign were 5.8 and $11.6 \mathrm{~L} / 1000$ patient-days, respectively $(\mathrm{p}<0.01)$. Moreover, the isolation rate of MRSA significantly decreased after the campaign from $2.5 \%$ to $1.5 \%(\mathrm{p}<0.01)$. Aggressive hand hygiene campaigns are useful to decrease the isolation rate of HA-MRSA.
\end{abstract}

Key words : hand hygiene, campaign, disinfectants, alcohol-based hand rub 